\section{Is there a wrong type of research for hospital pharmacy?}

\author{
Phil Wiffen
}

In the last 6 years or so as editor in chief of EJHP, I have seen a marked change in the quality of papers and in the underlying research submitted to EJHP. The culture of research is changing, and it seems that the desire to undertake research and to publish is growing. The editorial board (listed on the back cover) is now able to be more selective in terms of what is published, and we now reject around 60\% of submissions. That is a healthy position for the quality of the journal. The congress is also displaying similar interest in publishing research via posters. For this 2019 EAHP Congress, nearly 1200 submissions were made and just over 600 were accepted.

However, there does seem to be an underlying debate about what constitutes acceptable research with some proponents arguing that only primary bench research is of value. I take issue with this approach.

Some 20 years ago, a paper from the Royal Pharmaceutical Society in Britain ${ }^{1}$ defined pharmacy practice research as 'research which attempts to inform and understand pharmacy and the way in which it is practised in order to support the objectives of pharmacy practice and to ensure that pharmacists' knowledge and skills are used to the best effect in solving the problems of the health service and meet the health needs of the population'.

An even older statement from American Society of Health-System Pharmacists $^{2}$ suggests that pharmacists should

Correspondence to Professor Phil Wiffen, Pain Research Unit, Churchill Hospital, Oxford OX3 7LE, UK; phil.wiffen@ndcn.ox.ac.uk undertake pharmaceutical research, including the development and testing of new drug dosage forms and drug preparation and administration methods and systems.

It lists three areas which I would expand today.

- Clinical research, such as the therapeutic characterisation, evaluation, comparison and outcomes of drug therapy and drug treatment regimens.

- Health services research and development, including behavioural and socioeconomic research such as research on cost-benefit issues in pharmaceutical care.

- Operations research, such as time and motion studies and evaluation of new and existing pharmacy programmes and services.

To this list, I would add evidence-based approaches to effectiveness and service provision using systematic review methodology and also the role of audit which can provide an accessible entry into basic research and publishing. In addition, work that looks at stability and compatibility is of course also valuable.

As far as this journal is concerned, we will consider any research methods that produce results that are relevant to the wide range of practice within hospital pharmacy.

However, there are two other linked issues which I need to touch on. We are now rejecting sufficient papers that authors are going to be disappointed. Unfortunately for those of us who seek to aspire to publish regularly, that is a fact of life. I would encourage such authors to seek other outlets for their papers, there are plenty to choose from. Also, we are willing to reappraise decisions if authors feel they have good grounds to challenge a rejection.

It is important that good research does not remain unpublished and that leads me to my second concern which is the growing issue of research waste. Some have argued that over $50 \%$ of research remains unpublished. ${ }^{3}$ That is unacceptable and unethical especially if patients have contributed to the research in some way. Research that is not published is largely wasted, and it may be time to dust off that project in your desk drawer that you always meant to finish with a paper.

Finally, I have opined there is no wrong type of research however much research waste is created by poor design and poor conduct and analysis. Make sure your research is underpinned by good methodology.

Competing interests None declared.

Provenance and peer review Commissioned; internally peer reviewed.

(c) European Association of Hospital Pharmacists 2019. No commercial re-use. See rights and permissions. Published by BMJ.

(D) Check for updates

To cite Wiffen P. Eur J Hosp Pharm 2019;26:59.

Published Online First 4 February 2019

Eur J Hosp Pharm 2019:26:59.

doi:10.1136/ejhpharm-2019-001872

\section{REFERENCES}

1 Mays N. A new age for pharmacy practice research: promoting evidence-based practice in pharmacy. London: Royal Pharmaceutical Society, 1997.

2 American Society of Hospital Pharmacists. ASHP statement on pharmaceutical research in organized health-care settings. Am J Hosp Pharm 1991;48:1781.

3 Comment on Resaerch Waste. https://blogs.bmj.com/ bmj/2016/01/14/paul-glasziou-and-iain-chalmers-is-85of-health-research-really-wasted/ 